Bol. Acad. peru. leng. 51. 2011 (155-180)

\title{
COMPARACIÓN ENTRE TRES PERSONAJES FEMENINOS DE LA DIVINA COMMEDIA
}

\section{COMPARAISON ENTRE TROIS PERSONNAGES FEMININS DE LA DIVINE COMÉDIE}

\section{COMPARISON BETWEEN THREE FEMININE CHARACTERS OF THE DIVINE COMEDY}

\author{
Gabriel Martínez Vera \\ Universidad Antonio Ruiz de Montoya
}

\section{Resumen:}

En el presente ensayo, compararemos tres personajes femeninos de la Commedia: Francesca, Pia y Piccarda, tomando en cuenta dos perspectivas. La primera consiste en analizar su discurso en función de la totalidad de la obra a través de algunas coordenadas importantes en la Commedia y la segunda estriba en acercarnos directamente al papel que Dante-autor les da a los personajes femeninos que trabajaremos.

\section{Résumé:}

Dans cette étude nous allons faire une comparaison des trois personnages féminins de la Commedia: Francesca, Pia et Piccarda, en tenant compte des deux perspectives. La première consiste à analyser son discours en fonction de totalité de l'œuvre à travers de quelques données importantes dans la Commedia et la deuxième de s'adresser directement au rôle que Dante-auteur donne aux personnages féminins avec lesquels nous travaillerons. 


\section{Abstract:}

In this essay we are going to compare three female characters of the Commedia: Francesca, Pia and Piccarda, taking into account two perspectives. The first one consists to analyze their speeches and their function in the poem through some coordinates that are important in the Commedia and the second one is to approach directly to the role that Dante-author gives to the feminine characters we will work on.

Palabras clave:

Amor; justicia; victimización; femenino.

Mots clés:

Amour; justice; victimisation; féminin.

Key words:

Love; justice; victimization; feminine.

Fecha de recepción: $\quad 10 / 12 / 2010$

Fecha de aceptación: $\quad$ 25/02/2011

En el siglo XX, el rol de la mujer y de lo femenino adquirió progresivamente mayor relevancia social, lo cual se evidencia a través de la mayor inclusión de la mujer en los diversos campos de la vida pública, así como de la subversión de valores por los cuales la mujer quedaba a la sombra del varón. Por otra parte, la Divina Commedia es uno de los clásicos de la literatura universal, entre otros motivos, por la riqueza de recursos literarios e innovaciones estilísticas, pero también por su discurso y su resonancia en la sociedad de su tiempo y de la actualidad. Por ello, consideramos importante relacionar estos dos tópicos, de tal manera que podamos iluminar, en algún modo, la trayectoria de la idea de lo femenino en la historia y el papel de la mujer en la sociedad, y también el rol que la literatura le ha asignado a la mujer. 
Por estos motivos, en el presente ensayo buscaremos hacer una relación comparativa entre tres personajes femeninos de la Commedia: Francesca, Pia y Piccarda ${ }^{1}$, tomando en cuenta dos perspectivas. La primera consiste en analizar su discurso en función de la totalidad de la obra a través de algunas coordenadas importantes en la Commedia y la segunda estriba en acercarnos, directamente, al papel que Dante-autor les da a los personajes femeninos que trabajaremos.

Con el fin de cumplir nuestros objetivos, hemos dividido este artículo en tres secciones. En la primera, abordaremos brevemente el significado de las coordenadas del tiempo, el amor, la moral, la misericordia y la justicia en la obra, con el fin de establecer un marco teórico que nos permita analizar, comparativamente, el discurso de los personajes que hemos seleccionado, cuestión que trabajaremos en la segunda parte. Finalmente, en la tercera sección, nos acercaremos al rol de lo femenino, a partir de la igualdad en el juicio ante Dios en función de valores masculino, del papel de la mujer en los primeros cantos de cada cantiga de la obra y de la intervención del varón en el destino de ultratumba de los personajes trabajados.

\section{Las historias "para" y no "de": construcción de un marco teórico para el análisis del discurso de los personajes}

El primer aspecto común a los tres personajes que consideramos es que sus pequeñas historias cumplen una finalidad que no es contar su propia historia, sino contar su historia en función de la totalidad de la Commedia. Por ello, ninguno de los tres personajes maneja un discurso arbitrario, sino que las palabras que pronuncian ilustran el lugar en el que se encuentran. De este modo, Francesca tiene el papel de ilustrar el pecado a través del círculo de los lussuriosi del Inferno; Pia, la espera por la salvación eterna desde el segundo balzo del Antipurgatorio; y Piccarda, la beatitud en el Cielo de la Luna del Paradiso. Por este motivo, antes de abordar el papel de cada personaje en el lugar que ocupa, trabajaremos algunos aspectos que condicionan las palabras que dicen en la obra.

Identificadas con las contemporáneas de Dante: Francesca da Rimini, Pía de' Tolomei y Piccarda Donati, respectivamente. 
Desde esta perspectiva, en primer lugar, consideremos la dimensión del tiempo en las tres ciudades de ultratumba. Encontramos que el Inferno y el Paradiso están marcados por la dimensión de lo eterno. Aunque en ambas cantigas se reflejan los polos opuestos, a saber, el castigo en el Inferno y la salvación en el Paradiso, en los dos, dichos estados tienen la característica común de no terminar. El Inferno es la ciudad en la que la esperanza no tiene cabida, mientras que el Paradiso es el espacio de la felicidad imperecedera. En cambio, aunque el Purgatorio es una ciudad de ultratumba, es un espacio orientado hacia la eternidad del Paradiso. En este sentido, el Purgatorio es un lugar de paso, es decir, de carácter transitorio. Así, esta montaña quedará, eventualmente, vacía, porque en algún momento dejarán de haber pecadores con la necesidad de purgar sus culpas. En definitiva, encontramos que se encuentran dos concepciones del tiempo. Por un lado, están el Inferno y el Paradiso, en los cuales prima una concepción circular del tiempo; mientras que, por otro, en el Purgatorio transcurre el tiempo de modo lineal.

Para ilustrar ambas concepciones del tiempo, tomemos, en primer lugar, los versos del Canto $V$ del Inferno:

E come li stornei ne portan l'ali nel freddo tempo, a schiera larga e piena, così quel fiato li spiriti mali di qua, di là, di giù, di sù li mena; nulla speranza li conforta mai, non che di posa, ma di minor pena. (Alighieri 1973: 42)

Encontramos que el castigo en el círculo de los lussuriosi son voraces torbellinos, es decir, veloces arremetidas del viento en forma circular. Asimismo, estos vientos huracanados no cesarán, lo cual le da al castigo el talante de repetición constante y de carácter implacable e irremediable.

En el Paradiso, por otra parte, la descripción de los cielos es de carácter lineal, es decir, ascendente, aumentando en gloria y perfección. Ante la situación de los salvados en el Cielo de la Luna y su estado de beatitud, Beatrice le explica a Dante-personaje que: 
Così parlar conviensi al vostro ingegno, però che solo da sensato apprende ciò che fa poscia d'intelletto degno. Per questo la Scrittura condescende a vostra facultate, e piedi e mano attribuisce a Dio, e altro intende; (Dante 1973: 380)

De este modo, queda patente que la ordenación lineal del Paradiso cumple solamente una función pedagógica, por medio de la cual desde lo alto se ha dispuesto, por intercesión de Beatrice, que Dante-personaje conozca y viva su propio camino de salvación. Sin embargo, el culmen del Paradiso es la dimensión circular, en la cual cada personaje ocupa un lugar específico, según lo ha dispuesto la divinidad. Por consiguiente, el tiempo del Paradiso es la eternidad:

E sì come di lei bevve la gronda de le palpebre mie, così mi parve di sua lunghezza divenuta tonda. (Dante 1973: 517)

Estos versos son una alegoría del estado en el que se hallan dispuestos los bienaventurados en el Paradiso. Dante-personaje se encuentra próximo a contemplar a Dios y todos los salvados asumen el lugar que les corresponde. Encontramos, así, a través del símbolo del río, que el Paradiso tiene una forma circular. Como es sabido, el círculo es sinónimo de aquello inconmensurable e infinito. Por consiguiente, a partir de esta disposición del Paradiso tenemos que el tiempo en esta ciudad es eterno.

En medio de la condenación y salvación eternas, está la ciudad intermedia, la montaña del Purgatorio. Aunque esta es también un espacio de ultratumba, carece de la ausencia de cambio que sí poseen las otras dos: el Purgatorio está orientado hacia el Paradiso. En esta montaña, es tangible que el tiempo transcurre de un modo lineal. A lo largo del recorrido de Dante-personaje, muchos otros personajes le suplican que interceda por ellos en la Tierra, para que sus conocidos y familiares oren por ellos con el fin de que su tiempo de espera sea 
menor. En consecuencia, a diferencia de la realidad inmutable del Inferno y del Paradiso, en el Purgatorio, los vivos pueden aligerar la carga de los muertos. Por los ya condenados y salvados no hay nada que hacer, mientras que por aquellos que se están purificando, sí se puede colaborar desde la Tierra. El Purgatorio es, así, un lugar en el que se está en proceso.

Esta dimensión de proceso abierto, frente a los procesos cerrados del Inferno y el Paradiso, cambia la concepción del tiempo en el Purgatorio. Frente al reproche que Dante-personaje hace a Belacqua por quedarse reposando en lugar de dirigirse a las puertas de la montaña, este último le contesta:

Ed elli: "O frate, andar in sù che porta?

ché non mi lascerebbe ire a' martirio

l'angel di Dio che siede in su la porta.

Prima convien che tanto il ciel m'aggiri

di fuor da essa, quanto fece in vita,

perch'io 'ndugiai al fine i buon sospiri, (Dante 1973: 211)

De este modo, Belacqua debe esperar el mismo tiempo que vivió para entrar a purgar sus pecados. Por esta cuestión temporal, entre otras, se hace relevante el saber exactamente cuándo pasan los días, puesto que este transcurrir del tiempo hace que los que purgan sus culpas se acerquen un poco más al estado de beatitud perfecta. En consecuencia, encontramos que el tiempo en el Purgatorio es de carácter lineal. Por ello, argüíamos anteriormente que en algún momento dejarán de haber personas en él, puesto que existirá una época -utópica, quizás, o incluso hasta la llegada del Juicio Final- en la que no habrá nadie que purgue sus culpas.

Ahora bien, además de la dimensión temporal que acabamos de examinar, consideramos necesario trabajar brevemente algunos conceptos que articulan la estructura de la Commedia y que afectan directamente el discurso y el lugar que ocupan en la obra los tres personajes que trabajamos. 
El concepto más importante para articular la Commedia es el amor. Dios es por antonomasia amor, lo cual es notorio en los cantos finales de la obra, que son su culmen, puesto que en él, Dante-personaje termina su propio camino de salvación y entra en un éxtasis indescriptible. Este, desde la óptica divina -desde la cual pasa a la vida y manejo de la libertad de los seres humanos-, es entendido como una donación constante y total entre las tres divinas personas. La donación implica movimiento, puesto que requiere de la acción de salir de sí y entregarse a la otra persona. Lo opuesto al amor, el desamor, es, por lo tanto, lo contrario al movimiento, es decir, la inacción o el egoísmo radical que vuelca a la persona -o ser racional- sobre sí misma. Tal es el caso de Lucifero, que está anclado en el centro de la Tierra en medio del hielo y cuyo movimiento de alas, en lugar de ayudarlo a salir de su condición, lo ata más al frío, puesto que congela las aguas de los ríos que llegan a donde se encuentra. De este modo, encontramos que el Inferno es el lugar del desamor o de la inacción, mientras que el Paradiso es la ciudad del movimiento total.

Sin embargo, que el desamor sea sinónimo de la inacción no quiere decir que no haya movimiento. Tanto en el círculo de los lussuriosi como en el caso de Lucifero, encontramos movimiento, que incluso puede llegar a ser abrumador. El problema de este movimiento es que, en lugar de volcar al ser hacia la donación constante, lo encierra en sí mismo. Es, en consecuencia, un movimiento desorientado, porque rompe con la finalidad que desde lo alto se le ha asignado. De este modo, el torbellino del círculo de la lujuria encierra a los condenados sobre sí mismos, así como Lucifero está atado irremediablemente al hielo del centro de la Tierra. En cambio, en el Paradiso, el movimiento no es desesperado o inútil, sino que tiene una finalidad concreta. Por ello, en el Paradiso se encuentra una dinámica más armónica, en la que el movimiento de los astros es mayor cuando están más cerca del centro que los articula. En ciertos momentos, el movimiento en el Paradiso puede parecer incluso quietud, debido a que se expresa en la tranquilidad de la contemplación divina o en la paz de la comunicación de la beatitud. 
Este continuum de amor y desamor que constituyen el criterio fundamental de ultratumba -y de la Tierra, por ende- afecta, naturalmente, a los seres humanos, puesto que ellos son los que recibirán la salvación o condenación eternas. Para ilustrar este punto, Virgilio le explica a Dante-personaje que el amor es connatural a las criaturas, porque lo han recibido de su Creador. Sin embargo, si se pierde esta orientación, las consecuencias son terribles:

ma quando al mal si torce, o con più cura

o con men che non dee corre nel bene, contra 'l fattore adovra sua fattura. (Dante 1973: 277)

De este modo, si se pervierte este origen -el amor-, el ser humano se desorienta, lo cual constituye una obra contra Dios. Esta perversión constituye el pecado, según el cual se juzga a los seres humanos después de la muerte. De esta manera, el modo en que se haya vivido o no el amor se erige como una forma de juzgar el comportamiento moral a las personas.

Por ello, junto al criterio fundamental del amor y su aplicación concreta en la moral, está la justicia. La divinidad tiene la potestad de juzgar. Las referencias a este tópico son innumerables en la Commedia. Ya en el Canto III del Inferno queda patente, en el dintel de la puerta de este recinto, que Dios es justiciero. Más allá de detenernos en citas al respecto, queremos trabajar tres aspectos de la justicia divina que afectan directamente a nuestros personajes.

Por un lado, en el Inferno, los pecados, ya entendidos como una desorientación en el amor, son clasificados según la pasividad o actividad de los condenados. Por ello, los pecados pueden ser de pasión o de razón. Los segundos reciben peores castigos que los primeros, están más cerca de Lucifero y son confinados dentro de las murallas de la ciudad de Dite. Estos condenados están en los círculos más tortuosos del Inferno. Sin embargo, lo que nos compete directamente a nosotros son los pecados de pasión. Francesca y Paolo -a quien está unida en su condena- se encuentran en el círculo de los lussuriosi, el primero 
propiamente del Inferno. En el Limbo, aunque está la condena de no estar bajo el manto de la beatitud divina, lo cual es ya suficiente castigo por no haberse bautizado, no existe ningún mal agregado, como sí se evidencia desde el segundo círculo del Inferno. Francesca expresa bellamente lo característico de la pasión:

Amor, ch'a nullo amato amar perdona, mi prese del costui piacer sì forte, che, come vedi, ancor non m'abbandona. (Dante 1973: 44-45)

El condenado por la pasión es una víctima. Lo que percibe es que, desde fuera de sí, se le ha insertado algún deseo irremediable e irrevocable que lo seduce y lo obliga a actuar de un modo específico. De esta manera, el pecador de pasión no se siente responsable de lo que ha hecho, por lo que maldice a la divinidad. No obstante, en este punto es donde radica su pecado, debido a que no ha asumido la capacidad racional y, con ella, la libertad de contenerse y de decidir lo que le conviene o no para su salud. Por este motivo, a los condenados entre los círculos segundo y quinto se los llama, precisamente, incontinentes.

En segundo lugar, la justicia tiene una dimensión legal. Tanto en el caso del matrimonio, como en el de los votos religiosos, el ser humano hace un contrato. Este tiene la característica de ser hecho ante y con Dios, por lo que su incumplimiento acarrea consecuencias. Beatrice se lo explica a Dante en el Canto IV del Paradiso:

Per che, s'ella si piega assai o poco, segue la forza; e così queste fero possendo rifuggir nel santo loco. Se fosse stato lor volere intero, come tenne Lorenzo in su la grada, e fece Muzio a la sua man severo, così l'avria ripinte per la strada ond' eran tratte, come fuoro sciolte; ma così salda voglia è troppo rada. (Dante 1973: 382) 
Ante la violencia que se le hace a una persona, el deber de esta es defender su contrato ante el Sommo Bene sobre cualquier otro requerimiento. Por ello, aunque haya un castigo, no se debe ceder. Cualquier muestra de pusilanimidad es, desde la óptica de la justicia divina -construida bajo la égida de valores masculinos, como trabajaremos más adelante-, una evidencia de incumplimiento del voto pronunciado. De este modo, se confirma el hecho de que no se acepta la victimización, puesto que es ajena al uso de la voluntad y de la libertad. Los ejemplos de Lorenzo y Muzio son ilustrativos al respecto, ya que testimonian la entereza que se requiere para vivir cristianamente.

Finalmente, frente a lo implacable que se puede considerar a la justicia divina, existe una cláusula de misericordia. Aunque esta no exime al pecador del Purgatorio, es decir, de su necesidad de purificación antes de entrar en el Paradiso, sí lo salva de la condenación eterna del Inferno, $y$, por ende, de la imposibilidad de acceder a la beatitud eterna. Tal es el caso de los personajes que están en los rellanos del Antipurgatorio: excomulgados y arrepentidos en el lecho de la muerte. Tomemos algunos versos de los Cantos III y V del Purgatorio para ilustrarlo:

Orribil furon li peccati miei; ma la bontà infinita ha sì gran braccia, che prende ciò che si rivolge a lei. (Dante 1973: 205)

Noi fummo tutti già per forza morti, e peccatori infino a l'ultima ora; quivi lume del ciel ne fece accorti, (Dante 1973: 213)

El primer terceto son las palabras de Manfredo, un excomulgado, mientras que las segundas son el testimonio de aquellos que se arrepintieron en la última hora. Como podemos notar, frente a la dimensión pecadora existe siempre la oportunidad del arrepentimiento -que implica el uso de la libertad- y de recibir el perdón. La bondad de Dios acoge a aquel que reconoce sus faltas y lo coloca en el camino de la salvación, en tal grado, que reorienta su deseo y despierta nuevamente las ansias de estar ante Dios. 


\section{Las historias "de" desde el "para": análisis del discurso de los personajes}

Bajo el marco general que hemos propuesto, conviene ahora acercarnos al discurso de los personajes que trabajamos. En primer lugar, Francesca -y Paolo-, como mencionamos anteriormente, está en el círculo de los lussuriosi dentro de un torbellino imperecedero que la castiga. Tomemos el inicio de la conversación que sostiene con Dantepersonaje:

ì tosto come il vento a noi li piega, mossi la voce: "O anime affannate, venite a noi parlar, s'altri nol niega!”

Di quel che udire e che parlar vi piace, noi udiremo e parleremo a voi, mentre che 'l vento, come fa, ci tace. (Dante 1973: 44)

De este modo, el interés por conversar parte de Dante-personaje. Francesca y Paolo salen del torbellino por un momento y acceden con gusto, aunque reconocen que dependen de la clemencia o inclemencia del viento, el cual, por el momento, les ha dado una tregua. Sorprende al respecto que Francesca y Paolo sean tan cordiales con el peregrino. Están ya condenados y, por ello, el hecho de que se comuniquen con Dante-personaje no es relevante para ellos -mas no para él, puesto que es parte de su proceso como peregrino de ultratumba-, ya que no pueden salir de su estado. Como mencionamos anteriormente, su condición es irremediable, debido a que están condenados al castigo eterno. Sin embargo, existen otros motivos que mueven a los amantes a comunicarse afectuosamente con el protagonista:

Quali colombe dal disio chiamate con l'ali alzate e ferme al dolce nido vegnon per l'aere, dal voler portate; 
se fosse amico il re de l'universo, noi pregheremmo lui de la tua pace, poi c'hai pietà del nostro mal perverso. (Dante 1973: 44)

Son dos las motivaciones que mueven a los amantes a dirigirse a Dante-personaje: el amor y una especie de simpatía que se despierta en los condenados por el interés altruista del peregrino por el estado en que se encuentran. Es notorio también que, a diferencia de las maldiciones que suelen haber en el Inferno hacia Dios, Francesca y Paolo no mencionan a Dios de un modo peyorativo, sino que, al contrario, existe incluso una suerte de nostalgia por no poder fortalecer con una bendición al viajero.

Entonces, ¿cómo se explica que Francesca y Paolo se muestren cordiales y gentiles hacia Dante-personaje si están en la ciudad de los malditos? y ¿cómo es posible que el peregrino sienta compasión por la situación de los amantes? Consideramos que la respuesta radica en los criterios para la condenación y la salvación. Centrémonos solo en Francesca. Ella es un personaje cargado de amor: está atada al ser amado y su acto de comunicación con el viajero evidencia su capacidad de salir de sí, en lugar de encerrarse dentro de sí. De este modo, estar en el Inferno no hace a los condenados seres ajenos completamente a la bondad. Sin embargo, Francesca está en el Inferno porque no fue capaz de contenerse, se dejó convertir en víctima de la pasión:

Amor, ch'al cor gentil ratto s'apprende, prese costui de la bella persona che mi fu tolta; e 'l modo ancor m'offende. (Dante 1973: 44)

Encontramos, de este modo, que su amor está desorientado. Allí radica su gran culpa. La justicia divina se muestra condenatoria con ella porque no hizo uso de capacidad racional para manejar su voluntad, sino que, al procurar no decidir, eligió dejarse conducir a donde probablemente ella no hubiera llegado si se hubiera controlado. Ahora bien, su pecado es más grave porque, desde una perspectiva moral, Francesca es una adúltera. Estaba casada con Gianciotto Malatesta quien asesina violenta y repentinamente a los amantes, debido a lo cual 
Francesca se queja, ya que no tuvo oportunidad de arrepentirse de su pecado-, por lo que había hecho un contrato ante Dios, y falló. Vivir atada a su pasión es, por consiguiente, su condena. En consecuencia, su pecado gravita sobre ella más que su capacidad de amar.

El caso de Pia es diferente. Ella se encuentra en el segundo balzo del Antipurgatorio. Su perspectiva temporal es diferente: debe esperar que pasen tantos años como los que vivió en la Tierra para ingresar, propiamente, a la montaña del Purgatorio. La perspectiva con respecto a Dante-personaje es otra:

"Questa gente che preme a noi è molta, e vegnonti a pregar," disse "l poeta:

"però pur va, e in andando ascolta." (Dante 1973: 213)

Virgilio se dirige a su acompañado y le pide que no aminore el paso. Conoce de antemano que los que se encuentran en el Purgatorio buscarán la intercesión del protagonista con el fin de acortar la espera por expiar sus culpas y contemplar a Dios. Por ende, a diferencia de lo que sucede con Francesca, aunque el viajero, como lo muestra en toda la obra, es curioso y desea conocer sobre los personajes con quienes se encuentra, no tiene que tomar la iniciativa, sino que son otros quienes lo buscan. El viaje de Dante-personaje adquiere, por consiguiente, otra finalidad: ser intercesor en la Tierra de los pecadores del Purgatorio. Pia forma parte de este grupo que se acerca al viajero y solicita su intercesión.

Por otra parte, a diferencia de Francesca, su aparición en el escenario es repentina. No hay preámbulos sino solo el general, colocado al iniciar el Canto $V$, que es válido para todos los personajes que intervienen en los Cantos Vy VI del Purgatorio. De la misma manera, su intervención es breve: no conocemos, a partir de la obra, mayores datos sobre ella, sino que está envuelta en cierta oscuridad. Examinemos la primera parte de su discurso:

"Deh, quando tu sarai tornato al mondo

e riposato de la lunga via", 
seguitò 'l terzo spirito al secondo, "ricorditi di me, che son la Pia; (Dante 1973: 216)

Lo primero que llama la atención, es que a Pia, mas no a Francesca, sí le interesa que Dante-personaje esté vivo. La simpatía hacia el viajero que se evidencia en el texto, al hacer mención que descanse de su viaje, no está dada por la compasión que el peregrino sienta hacia ella, sino por lo que él puede hacer por ella cuando vuelva al mundo de los vivos. Lo segundo, es que Pia no es un personaje que centre la totalidad de la atención del protagonista -como sí lo hacen los amantes-, sino que forma parte de un conjunto de hablantes que aparecen tanto en el Canto $V$ como en el VI: Pia es el "terzo spirito" que habla.

Empero, consideramos que la segunda parte de su discurso resulta más interesante para nuestros propósitos:

Siena mi fé, disfecemi Maremma:

salsi colui che 'nnanellata pria

disposando m'avea con la sua gemma”. (Dante 1973: 216)

Al igual que Francesca, Pia recibe una muerte violenta. Sin embargo, esta última sí se arrepintió de su pecado y, por ello, está en el Purgatorio. No obstante, no sabemos cuál es su pecado: según algunos estudiosos, le fue infiel a su marido y según otros, él quería a otra mujer. Asimismo, tampoco tenemos mayores datos sobre su capacidad de amar: no hay ninguna referencia, sino solo su muestra de simpatía hacia Dantepersonaje -que no sabemos cuán desinteresada es-. En definitiva, lo único que sabemos es que Dios tuvo misericordia de ella. Consideramos, a partir de estos datos, que la diferencia fundamental sobre estos puntos entre Pia y Francesca es que la primera no fue víctima de sus pasiones, sino que tomó una decisión: arrepentirse de su pecado en el lecho de muerte. Este hecho cambia sustancialmente su destino: Francesca está condenada al Inferno, mientras que Pia camina hacia la salvación eterna del Paradiso.

Por último, seguimos ascendiendo para encontrarnos en el Cielo de la Luna con Piccarda Donati. Ella, al igual que Francesca, se encuentra 
en una situación marcada por la eternidad, aunque no como suplicio imperecedero, sino como beatitud. La situación comunicativa entre ella y Dante-personaje es diversa a la de los encuentros que analizábamos anteriormente. Beatrice le dirige estas palabras al viajero:

Però parla con esse e odi e credi;

ché la verace luce che le appaga

a sé non lascia lor torcer li piedi." (Dante 1973: 375)

En este encuentro, interviene un tercero con el fin de motivar la conversación. Beatrice actúa como motivadora de Dante-personaje para que este se empiece a sumergir en la beatitud del Paradiso. Encontramos, de este modo, que es Dios, quien quiere comunicarse al peregrino en el Paradiso, puesto que Beatrice es su mediadora directa ante Dantepersonaje. El viajero no vacila al recibir esta indicación y actúa en consecuencia:

E io a l'ombra che parea più vaga

di ragionar, drizza'mi, e cominciai, quasi com' uom cui troppa voglia smaga:

"O ben creato spirito, che a' rai

di vita etterna la dolcezza senti

che, non gustata, non s'intende mai,

grazioso mi fia se mi contenti

del nome tuo e de la vostra sorte”. (Dante 1973: 376)

Llama la atención, en primer lugar, que el receptor, Piccarda, está ansioso por hablar. No obstante, este deseo no es exclusivo de él, sino que Dante-personaje, que se ha dejado inflamar por las palabras de Beatrice, se siente movido a salir de sí y entablar una conversación con Piccarda. Al igual que en el diálogo con los amantes, el viajero se muestra muy cordial, pero hay algo más: en este caso, sí se produce la bendición que en el Inferno era imposible. En este punto, encontramos una diferencia en el lugar en que se ubican los tres personajes que trabajamos en los espacios, en los que se encuentran al conversar con el protagonista. Cuando Francesca habla con Dante, sale del torbellino en que se encuentra. Del 
mismo modo, Pia forma parte de un grupo de personas que se acerca a Dante-personaje a pedir su intercesión en la Tierra. Es decir, ambas salen de los lugares en los que se encuentran, cambian su posición. Sin embargo, Piccarda permanece en su lugar y es Dante-personaje quien se le acerca. De este modo, Francesca y Pia salen de su rutina cotidiana para conversar con el peregrino, mientras que Piccarda está en un lugar que no requiere de cambios. En definitiva, el lugar que ocupan los personajes mencionados al momento de conversar con Dante-personaje reflejan sus circunstancias en ultratumba: Francesca está condenada, Pia está en camino de purificación, por lo que para hablar con un vivo tienen que cambiar, en lo posible, de estado, pero Piccarda se encuentra ya en un estado de beatitud perfecta que no necesita modificaciones.

Finalmente, Piccarda toma la palabra y empieza a contar su historia:

Ond' ella, pronta e con occhi ridenti:

"La nostra carità non serra porte

a giusta voglia, se non come quella

che vuol simile a sé tutta sua corte. (Dante 1973: 376)

La cordialidad de Piccarda es notoria, ya que, como ella lo menciona, la caridad del lugar donde se encuentra viene de Dios. Ella responde con un corazón generoso al saludo cordial que el viajero le dirigió. De este modo, queda confirmada la presencia divina en el diálogo, tal como lo mencionábamos anteriormente con la invitación de Beatrice a Dante-personaje a hablar. De la misma manera, a través de los encuentros revisados, la acción divina en el camino de la Commedia se hace más tangible en la medida en que Dante-personaje recorre su propia vía de salvación y abre su ser entero a la intervención de Dios. A diferencia de los encuentros de Dante-personaje con Francesca y Pia, la iniciativa no es exclusivamente del emisor, sino que es compartida también por el receptor. En el encuentro con Piccarda, la iniciativa por iniciar una conversación no está exclusivamente en el protagonista, pero tampoco lo está únicamente en Piccarda, y, además, interviene un tercer personaje: la representante de Dios, Beatrice. En definitiva, existe reciprocidad entre el peregrino y la beata: el deseo de comunicarse es mutuo. 
Ahora bien, en medio de esta conversación, cuyo inicio hemos trabajado brevemente, es necesario recalcar un aspecto de lo que hemos llamado presencia divina: el amor. Aquello que es característico en el diálogo que sostienen Dante-personaje y Piccarda es el deseo de salir de sí y comunicarse con el otro. Esta donación constante es lo que, como anteriormente hemos mencionado, marca al amor. No obstante, a diferencia del caso de Francesca, que vivió el amor de un modo errado, en el Cielo de la Luna -y en todo el Paradiso-, el amor está orientado hacia el Sommo Bene y Dante-personaje lo intuye así:

\author{
Ond' io a lei: "Ne' mirabili aspetti \\ vostri risplende non so che divino \\ che vi trasmuta da' primi concetti: (Dante 1973: 376)
}

Para el viajero, Piccarda es una muestra de la presencia de Dios. Dios transforma lo primitivo y lo convierte en nuevo, de tal manera, que pasa a ser prodigioso. En un primer momento, Dante-personaje no sabe decir exactamente en qué consiste ese "risplendi", sino que solo lo presiente. Por ello, se hace necesario que Piccarda explique un poco más en qué consiste la caridad divina:

"Frate, la nostra volontà quïeta
virtù di carità, che fa volerne
sol quel ch'avemo, e d'altro non ci asseta.

Anzi è formale ad esto beato esse enersi dentro a la divina voglia, per ch'una fansi nostre voglie stesse; (Dante 1973: 377)

Piccarda enfatiza, en primer lugar, la orientación del amor hacia el Sommo Bene. De esto se deriva que el anhelo humano debe ser uno con el divino y, de este modo, ser feliz. No obstante, este deseo debe manifestarse a través de la voluntad: el amor no se queda únicamente en buenos sentimientos, sino que conduce a tomar decisiones, es decir, a mover el querer hacia Dios. Existe, en este punto, una diferencia entre Piccarda y Pia: en el caso de la primera, se da una respuesta de 
la criatura hacia el Creador, puesto que busca unir su deseo y su querer con el de Dios; mientras que en la segunda, el énfasis está en el perdón que Dios otorga, es decir, en su misericordia. Piccarda procuró conducir su vida y tomar sus decisiones sobre la base del amor; en cambio, Pia esperó hasta el último momento para reorientar sus deseos y dirigirlos hacia la divinidad. En consecuencia, Piccarda, a diferencia de Pia -y de Francesca, que vivía pasivamente y, por lo tanto, en la inacción-, es una mujer activa, porque no se convirtió en víctima, sino que fue agente de los actos que realizó en vida.

Sin embargo, antes de terminar este punto, conviene hacer alusión al defecto de Piccarda. Ella no es solo una manifestación del amor, sino que hace patente también la acción de la justicia divina. Dante-personaje la interroga sobre si desearía estar en un lugar más alto del Paradiso y Piccarda le responde:

E questa sorte che par giù cotanto, però n'è data, perché fuor negletti

li nostri voti, e vòti in alcun canto." (Dante 1973: 376)

El amor de Piccarda falló en un voto porque, como mencionamos anteriormente, no tuvo la entereza de Lorenzo o Muzio para que no la saquen del convento y su hermano, el violento Corso, la obligue a casarse. Aunque, desde el punto de vista sociopolítico de la época en que vivió Piccarda, es perfectamente comprensible que haya salido del convento porque su hermano la obligara a ello; sin embargo, como lo explica Beatrice en el Canto IV del Paradiso, no se justifica el incumplimiento del voto que había prometido al entrar en la clausura:

Se violenza è quando quel che pate nïente conferisce a quel che sforza, non fuor quest' alme per essa scusate:

ché volontà, se non vuol, non s'ammorza, ma fa come natura face in foco, se mille volte vïolenza il torza. (Dante 1973: 381-382) 
Piccarda es culpable por haber cedido ante su hermano y aceptar, aunque forzada, lo que este quería. La justicia divina recae sobre Piccarda porque no fue fiel -de un modo inquebrantable- al contrato que había hecho con Dios al ingresar al claustro. En otras palabras, el amor de Piccarda estuvo desorientado, puesto que reemplazó al Sommo Bene para complacer a Corso.

\section{El rol de lo femenino ${ }^{2}$}

Una vez examinados los discursos de Francesca, Pia y Piccarda, nos gustaría tratar brevemente la cuestión de género que brota de la comparación que hemos trabajado. Sin embargo, antes de detenernos en algunos aspectos, consideramos relevante situarnos en cierta perspectiva. Aunque los personajes femeninos tienen funciones importantes en la Commedia, tales como la guía e intercesión de Beatrice o la presencia de Matelda en el Purgatorio, encontramos, solo por mencionar un dato curioso, que el número de mujeres en la obra, en comparación al de varones, es infinitamente menor. ${ }^{3}$ En consecuencia, aquello que digamos con respecto al rol de lo femenino en el poema a partir de los personajes que comparamos, estará supeditado, a priori, no solo a la desigualdad numérica evidenciada en la Commedia, sino también a la subordinación que vivía la mujer con respecto al varón en la Edad Media.

Ahora bien, consideremos, en primer lugar, el tema de la justicia en el juicio a los muertos. Sustentamos que en la Commedia existe una igualdad entre varones y mujeres ante Dios, aunque dicha igualdad es en función de valores asociado al rol de lo masculino. Asimismo, la idea de la igualdad, aunque importante en el tratamiento de género en

2 No abordaremos en este apartado dos aspectos que ya hemos trabajado en el subcapítulo anterior: la infidelidad, tanto en el matrimonio como en los votos religiosos, y la pasividad o victimización. Estas dos cuestiones marcan el rol de lo femenino en los tres personajes que hemos trabajado, no obstante, hemos preferido tratarla anteriormente porque consideramos que eran claves para entender las nociones de amor, justicia, etc., que postulamos en la primera sección de este trabajo.

3 Únicamente por poner un ejemplo, en el Inferno encontramos mencionadas solo 16 mujeres, frente a la abundancia de varones en todos los círculos. 
la actualidad, no lo es tanto para la escatología cristiana, en la cual se sostiene que en la vida eterna se es como ángeles, es decir, como seres asexuados. Con el fin de trabajar este punto, abordaremos brevemente algunos aspectos de los personajes trabajados.

Por una parte, con respecto al caso de Francesca, como mencionábamos anteriormente, es condenada por la lujuria. Sin embargo, este pecado no es exclusivo de las mujeres: entre los condenados en este círculo encontramos a Semiramìs, a Cleopatràs, a Dido y a Elena, pero también a Parìs, a Achille y a Tristano. De este modo, reciben el mismo castigo varones y mujeres. En consecuencia, tanto hombres como mujeres, en el círculo de los lussuriosi, han sido juzgados de la misma manera por la justicia divina.

Por otra parte, en el caso de Pia, encontramos la misma realidad. Pia comparte el segundo balzo del Antipurgatorio con todos los arrepentidos en la última hora. De este modo, Pia, en el Canto V, comparte su camino junto a Jacopo del Cassero y Buonconte da Montefeltro. En el Canto VI seguirá el desfile de almas que le suplican al protagonista su intercesión entre los vivos. Del mismo modo, Pia, por ser mujer, no recibe ningún trato diferencial, sino que es, solamente, el "terzo spirito" que se dirige a Dante-personaje. Por consiguiente, encontramos también que no hay trato diferencial para hombres y mujeres entre los perdonados en la última hora.

Finalmente, con respecto a Piccarda, el caso es un poco diferente. En el Cielo de la Luna, no hay mayores personajes, sino solo Constanza y Piccarda. Además, a Constanza no la conocemos sino a través de Piccarda. Comparten el mismo grado de beatitud y la misma historia en la Tierra. Ambas están en ese cielo porque hubo un defecto en el cumplimiento de los votos. No obstante, en el Canto IV del Paradiso, Beatrice acude a ejemplos de santos que nos permiten plantear la cuestión de la igualdad ante Dios con respecto al cumplimiento de los votos. La guía del peregrino hace referencia a dos santos varones, Lorenzo y Muzio, que fueron sometidos a grandes tormentos por no claudicar de sus convicciones, tal como citamos en el primer apartado. De este modo, la justicia divina es igual para hombres y mujeres en el cumplimiento de los votos y, con toda seguridad, 
si Dante-autor hubiera querido colocar a un varón en este cielo, hubiera encontrado a algún personaje masculino para hacerlo. En consecuencia, no hay distinción de género ante Dios en el Cielo de la Luna: el juicio por fallar en un voto no es exclusivo para las mujeres.

Ahora bien, para concluir este primer aspecto, como hemos mencionado anteriormente, a los personajes que estudiamos se los condena por no hacer uso de su voluntad -en el caso Francesca- o por no mantenerla inquebrantable -en los casos de Pia y Piccarda-. Lo interesante al respecto es que a estas mujeres se les pide que asuman una conducta que no es propia de su rol social en la época: la mujer no tiene poder de decisión ni para elegir con quién casarse ni para participar en la vida pública, por solo poner dos ejemplos. Quien puede hacer uso de su voluntad es el varón. De este modo, a los personajes que trabajamos se los condena por no asumir un rol que no les correspondía en la sociedad de su tiempo: se las condena por no actuar según el modelo de acción masculino. Testimonio de ello es que la mayoría de personajes con el que estas tres mujeres son comparadas son varones. En consecuencia, la igualdad en el juicio ante Dios está supeditada a un modo masculino de proceder, por lo que a lo que se tiende es a que la mujer se convierte, en su modo de actuar, en un varón, lo cual fortalece, una vez más, la subordinación de la mujer al varón en la obra y en la sociedad medieval.

En segundo lugar, encontramos que Francesca, Pia y Piccarda constituyen un pórtico a las cantigas en las que están, respectivamente. Por una parte, el Inferno propiamente dicho empieza en el Canto $V$ de dicha cantiga, justo cuando han cruzado Virgilio y Dante-personaje el Acheronte, símbolo del paso del mundo de los vivos al mundo de los muertos en el mundo grecolatino. Antes de este círculo, estaban el Limbo y el círculo de los ignavi, los cuales no son, en sentido estricto, lugares de condena. Por ello, el Canto V constituye el umbral del Inferno. En este canto, Francesca, más que Paolo, es la que tiene la palabra y la que conversa con Dante. Es más, su discurso puede ser interpretado como una alegoría de la causa general de condenación de todos aquellos que están en el Inferno: una desorientanción en el amor. De este modo, Francesca es aquella que introduce a Dantepersonaje en el viaje por el Inferno. 
Por otra parte, aunque quizás el papel de Pia como un pórtico del Purgatorio sea menos notorio, encontramos, al respecto, tres datos interesantes. Está, por un lado, la simpatía que inspira esta mujer, de tal manera, que los estudiosos de la Commedia, a lo largo de los siglos, se han insipirado en ella para sus propias obras artísticas o de crítica literaria. Por otra lado, no deja de llamar la atención el hecho de que Pia sea la única mujer en los cantos referidos al Antipurgatorio que tenga la palabra. Al igual que Francesca -que cuando termina de hablar provoca el desmayo de Dante-personaje- y Piccarda -que se aleja de Dante-personaje cantando el Ave-, Pia, a través de una presencia fugaz, tiene la última palabra en el Canto V del Purgatorio. Finalmente, encontramos, si nos valemos de una interpretación quiasmática, que la presencia de Pia está en el centro de los cantos referidos al Antipurgatorio: son siete los cantos referidos a esta zona: del Canto II al Canto VIII, colocados entre la llegada de Virgilio y Dante-personaje a la montaña y el acceso al Purgatorio propiamente dicho. Pia se encuentra en el Canto $V$, que constituye el centro de dichos cantos. De este modo, este canto se erige como el punto álgido entre dichos cantos y adquiere una relevancia especial al tener ella la última palabra en él. Por consiguiente, el rol de Pia se erige como el culmen de los cantos introductorios del Purgatorio, que preparan a Dante-personaje para su ingreso en la montaña de la purificación.

Finalmente, el rol de Piccarda como pórtico en el Paradiso es más evidente. Hasta ingresar al Cielo de Luna, solamente Dante-personaje y Beatrice está en escena. Piccarda es la primera salvada -excluyendo a Beatrice, naturalmente, cuyo rol, además, no se circunscribe únicamente a la tercera cantiga- que acoge al viajero en el Paradiso. Este recibimiento no es de cualquier índole, puesto que le explica al protagonista el ordenamiento de la felicidad en el Paradiso, así como la definición del amor verdadero: ajustar el propio querer con el del Sommo Bene. Más aún, Piccarda no habla solo en nombre de ella, sino que lo hace también en nombre de Constanza, que comparte su historia. De este modo, Piccarda tiene varios pequeños roles que enriquecen el inicio del Paradiso, por la multiplicidad de temas que trata y por la profundidad con que lo hace, y, por ello, reviste esta cantiga de solemnidad. Piccarda introduce, de este modo, a la grandeza del Paradiso. 
Ahora bien, como mencionábamos anteriormente, el mundo medieval se caracterizaba por la subordinación de la mujer con respecto al varón. Como hemos visto, Dante-autor le da un papel sublime a los personajes femeninos que hemos trabajado, sin embargo, este aspecto no es obviado. Encontramos, de este modo, que su relación con los varones ha marcado su situación en ultratumba.

Por una parte, está Francesca, quien se encuentra en el Inferno por adúltera, aunque ella, más bien, se queje por no haber tenido la opción de arrepentirse: su esposo la mató antes de que pudiera discernir su conducta y tener la posiblidad de enmendarse. Por ende, aunque no culpamos a Gianciotto Malatesta de la mala fortuna de Francesca en el sentido de que su salvación depende de sus propias decisiones, y que ella decidió, precisamente, no decidir, sino ser una víctima de la pasión, sí consideramos que su condenación eterna estuvo marcada por su condición de esposa.

En segundo lugar, encontramos que el destino de Pia está también, en cierta medida, condicionado por su condición de esposa. Sea porque ella era infiel o porque su esposo lo fuera, lo cierto es que Pia fue asesinada. En este punto, tenemos que tanto Francesca como Pia fueron matadas violentamente por varones. Dos hombres fueron los responsables de que murieran antes de tiempo. Asimismo, Pia recibe el perdón de Dios porque deja de odiar a su esposo, Nello dei Pannocchieschi, lo que indica que su condición de pecadora en vías de salvación eterna estuvo ligada a la presencia de un varón en su vida. Por ende, al igual que Francesca, sus decisiones, así como su estado en ultratumba, estuvo enlazada con la presencia del varón en su vida y las decisiones que tomó ante dicha presencia.

Finalmente, en el caso de Piccarda, encontramos también que su estado de beatitud eterna está marcado por la presencia de un varón: su hermano Corso. Aunque, al igual que en Francesca y Pia, como hemos mencionado ya, en Piccarda exista cierto grado de pasividad y victimización, no podemos dejar de decir que su falta de entereza estuvo marcada por la presión que ejerció su hermano sobre ella. Por esta situación, Piccarda falló en uno de sus votos y, por ello, se encuentra en el Cielo de la Luna y no en 
otro de mayor beatitud. En consecuencia, la acción de un varón marcó la vida de Piccarda, puesto que la hizo dejar su condición de monja para pasar a ser esposa; y, además, esta situación provocó un cambio en su condición en ultratumba, debido a que falló en el cumplimiento de sus votos.

\section{Conclusión}

Una vez terminadas nuestras reflexiones, recapitulemos los puntos álgidos tratados en cada sección. En la primera, mencionábamos que los personajes trabajados, más que relatarnos su vida, cumplen con la misión de narrar cierta parte de su historia en función de la totalidad de la obra. Por ello, para enmarcar el análisis de sus discursos, abordamos la cuestión temporal, que difiere entre la eternidad del Inferno y el Paradiso y la linealidad del Purgatorio. Del mismo modo, reflexionamos brevemente sobre los conceptos de amor, moral y justicia, con sus respectivas variantes.

Por otra parte, en la segunda sección, nos centramos en el análisis comparativo de los discursos de los personajes trabajados. Tratamos la relación comunicativa entre cada personaje y Dante-personaje, situación que variaba según la aplicación de los aspectos trabajados en la primera parte a Francesca, Pia y Piccarda. El segundo aspecto relevante fue la importancia de la libertad y la orientación del querer con la voluntad de Dios. Cualquier falla o muestra de pasividad o victimización es condenada por la justicia divina.

Por último, con respecto al tercer apartado, encontramos que en la Commedia existe una tensión con respecto al rol de lo femenino. Por un lado, los personajes femeninos reciben la misma justicia que los masculinos y tienen funciones de gran envergadura en el poema que van más allá del rol de Beatrice-; sin embargo, por otro, no solo la abrumadora supremacía de personajes masculinos, sino la decisiva acción de los varones en el destino de los personajes trabajados, reflejan la subornidación en la que la mujer medieval vivía respecto al varón. 


\section{BIBLIOGRAFÍA}

ALIGHIERI, Dante. La Divina Comedia. Madrid, Alianza Editorial, 2000. . La Divina Comedia. Madrid, Espasa, 1999.

. The divine comedy. Nueva York, Bantam Books, 1982. . Obras Completas. Madrid, B. A. C, 1973.

BERGIN, Thomas. "Lectura Dantis: Inferno V", Charlottesville, University of Virginia, 1986.

BLOOM, Harold. El canon occidental. Barcelona, Anagrama, 1995.

CHIAPPO, Leopoldo. Dante y la psicología del Infierno. 2da. ed., Lima, Universidad Peruana Cayetano Heredia, 1986.

DUBY, Georges y PERROT, Michelle (eds.). Historia de las mujeres. T. IV, Madrid, Taurus, 1992.

FLEMING, Ray. "Francesca's Sweet New Subversive Style”, Lectura Dantis, No3, Fall, 1988, pp. 11-22.

GARABELLO SANGUINETTI, Federico. "Francesca y Ghismonda”, en Tenzone, No. 5, Madrid, Universidad Complutense, 2004.

GLENN, Diana. Dante's Reforming Mission and Women in the Comedy. Leicester, Troubador Publishing, Inc., 2008.

. "Of Thieves and Salvation Victories: Purgatorio V, 133", en BAKER, Margaret y GLENN, Diana (eds.). Dante Colloquia in Australia: 1982-1999. Adelaide, Australian Humanties Press, pp. 66-72, 2000.

LANSING, Richard. "Canto III: Piccarda Donati and the Poetics of Paradox", Berkeley and Los Angeles, University of California, 2007.

. The Dante Encyclopedia. Nueva York, Garland Publishing, Inc., 2000. 
LEVINE, Peter. "Why Dante damned Francesca da Rimini”, en Philosophy and Literature, No. 23.2. Baltimore, Project MUSE, pp. 334-350, 1999

WIESSE, Jorge (ed.). La divina comedia: voces y ecos. Lima, Universidad del Pacífico, 2008.

Biblia de Jerusalén. Bilbao, Descleé de Brouwer, 1998.

\section{Correspondencia:}

\section{Gabriel Martínez Vera}

Estudiante de la Universidad Antonio Ruiz de Montoya.

Correo electrónico: gabrielmartinezv@yahoo.com 